\title{
The distribution of jhp0940, jhp0945, jhp0947, jhp0949 and jhp0951 genes of Helicobacter pylori in China
}

\author{
Yanan Gong ${ }^{1,2}$, Xianhui Peng ${ }^{1,2}$, Lihua He $e^{1,2}$, Hao Liang ${ }^{1,2}$, Yuanhai You ${ }^{1,2}$ and Jianzhong Zhang ${ }^{1,2^{*}}$
}

\begin{abstract}
Background: The plasticity region of Helicobacter pylori (H. pylori) is a large chromosomal segment containing strain-specific genes. The prevalence of the plasticity region genes of the $H$. pylori strains in China remains unknown. The aim of this study was to examine the status of these genes and to assess the relationship between the genes and the diseases caused by H. pylori infection.

Methods: A total of 141 strains were isolated from patients with chronic active gastritis (CAG), peptic ulcer disease (PUD) and gastric carcinoma (GC). The prevalence of jhp0940, jhp0945, jhp0947, jhp0949 and jhp0951 was determined using PCR, and the results were analyzed using the chi-squared test.

Results: The prevalence rates of jhp0940, jhp0945, jhp0947, jhp0949 and jhp0951 in the H. pylori strains were 42.55, 51.06, 20.57, 56.03 and $63.12 \%$, respectively. The prevalence rates of jhp0940 were similar in the isolates from the CAG, PUD and GC patients, and there was no association between the jhp0940 status and any of the diseases. In contrast, the prevalence rates of jhp0945, jhp0947, jhp0949 and jhp0951 were significantly higher in the PUD and GC isolates than in the CAG isolates $(p<0.01)$. A univariate analysis showed that jhp0945, jhp0947, jhp0949 and jhp0951 increased the risk of PUD, while only jhp0951 was significantly associated with PUD in the multivariate analysis $(p=0.0149)$. The jhp0945-positive isolates were significantly associated with an increased risk for GC ( $p=0.0097)$.

Conclusion: The plasticity region genes are widely distributed in Chinese patients, and a high prevalence of these genes occurs in more serious diseases. Therefore, jhp0951 status is an independent factor associated with the development of PUD, and jhp0945 may predict the future development of GC in patients with CAG and is considered to be the best candidate disease marker for H. pylori-related diseases.
\end{abstract}

\section{Background}

H. pylori is the major cause of chronic gastritis, peptic ulcer disease, gastric carcinoma and mucosa-associated lymphoid tissue lymphoma [1,2]. The majority of infected individuals remain asymptomatic throughout their lifetime, and only approximately $15 \%$ develop gastroduodenal diseases. Variations in the clinical outcomes of these diseases have been attributed to differences in environmental factors, bacterial strains and host genetics $[3,4]$. A number of bacterial virulence factors that are

\footnotetext{
* Correspondence: zhangjianzhong@icdc.cn

'State Key Laboratory of Infectious Disease Prevention and Control, National Institute for Communicable Disease Control and Prevention, Chinese Center for Disease Control and Prevention, 155 Changbai Road, Changping District, Beijing 102206, China

${ }^{2}$ Collaborative Innovation Center for Diagnosis and Treatment of Infectious Diseases, Hangzhou, China
}

associated with these diseases have been described for $H$. pylori, such as the cag pathogenicity island (cag PAI) $[5,6]$.

A comparison of the genomes of two $H$. pylori strains revealed that in addition to the cag PAI, a large region of approximately $45 \mathrm{~kb}$ in strain $J 99$ and $68 \mathrm{~kb}$ in strain 26695 is present in both strains and has been termed the "plasticity region" $[7,8]$. Up to $50 \%$ of the strainspecific genes transferred from other species are located in the plasticity region [9]. Whether these strain-specific genes influence the severity of different diseases or the biological functions of the ORFs in the plasticity region still remains unknown. Recent studies have revealed that the jhp0940, jhp0945, jhp0947, jhp0949 and jhp0951 genes from $H$. pylori are associated with an increased risk for gastroduodenal diseases [3, 9-11]. In a Brazilian 
study, the jhp0947 gene was found to be involved in the development of duodenal ulcers (DUs) and GC [11]. In addition, Romo-González et al. found that jhp0951 is also associated with DUs [9]. In China, the number of $H$. pylori infections has exceeded $60 \%$, and the high-risk incidence of GC poses a serious health and economic burden. Moreover, there are no reports discussing the prevalence of these genes or the relationship between the genes and the severity of the clinical outcomes of the abovementioned diseases in China. The aim of this study was to assess the prevalence of jhp0940, jhp0945, jhp0947, jhp0949 and jhp0951 and to determine their association with $H$. pylori-related diseases.

\section{Methods}

\section{Strains}

A total of $141 \mathrm{H}$. pylori strains were selected from the $H$. pylori strain bank of China at the National Institute for Communicable Disease Control and Prevention, Chinese Center for Disease Control and Prevention. A total of 40 strains were isolated from patients in Heilongjiang (HLJ) Province (located in northern China), and another 101 strains were isolated from patients from Jiangxi (JX) Province (located in southeast China). These strains were related with CAG only $(n=58)$, PUD $(n=45)$ or GC $(n=38)$. Two strains with fully sequenced genomes, including strain 26695, which was isolated from a gastritis patient, and strain J99, which was isolated from a patient with a duodenal ulcer, were used as controls. This study was approved by the Ethics Committee of National Institute for Communicable Disease Control and Prevention, Chinese Center for Disease Control and Prevention. The written informed consent was obtained from all patients.

\section{Culture and extraction of genomic DNA}

The strains stored in brain heart infusion in $-80{ }^{\circ} \mathrm{C}$ were recovered on Columbia agar plates (Oxoid) supplemented with $5 \%$ fresh defibrinated sheep blood and kept under microaerophilic conditions (5\% O2, $10 \%$ $\mathrm{CO} 2$ and $85 \% \mathrm{~N} 2$ ) at $37{ }^{\circ} \mathrm{C}$ for 3 days. Colonies displaying typical $H$. pylori morphology were selected and identified by Gram staining and urease, oxidase, and catalase activity testing. The bacterial cells on chocolate agar plate were washed twice with phosphate buffer saline (PBS, pH7.5) and centrifuged at $5000 \mathrm{rpm}$ for $10 \mathrm{~min}$. The chromosomal DNA was extracted using the QIAamp DNA Mini Kit (Qiagen, Germany) according to the manufacturer's instructions.

\section{Determination of the jhp0940, jhp0945, jhp0947, jhp0949} and jhp0951 status via PCR

The status of the genes was determined via PCR using the primer pairs shown in Table 1. The amplification of
Table 1 The primer sequences for the five genes

\begin{tabular}{|c|c|c|c|}
\hline $\begin{array}{l}\text { Primer } \\
\text { name }\end{array}$ & Primer sequence $\left(5^{\prime}-3^{\prime}\right)$ & Product size & Reference \\
\hline \multirow[t]{2}{*}{ jhp0940-1 } & F5'-GAAATGTCCTATACCAATGG & $591 \mathrm{bp}$ & [3] \\
\hline & R5'-CCTAAGTAGTGCATCAAGG & & \\
\hline \multirow[t]{2}{*}{ jhp0940-2 } & F5'-ATGCCAACCATTGATTITACTITा & $978 \mathrm{bp}$ & {$[12]$} \\
\hline & R5'-TTATCGTCTACGCTTAGGTGTG & & \\
\hline \multirow[t]{2}{*}{ jhp0945 } & F5'-CAATGCGACTAACAGCATAG & $1028 \mathrm{bp}$ & [3] \\
\hline & R5'-CGCATTTGCTGTCATCTITG & & \\
\hline \multirow[t]{2}{*}{ jhp0947 } & F5'-GATAATCCTACGCAGAACG & $611 \mathrm{bp}$ & {$[3]$} \\
\hline & R5'-GCTAAAGTCATTTGGCTGTC & & \\
\hline \multirow[t]{2}{*}{ jhp0949 } & F5'-TTCAAAAAGTCCCCGAAATG & $235 \mathrm{bp}$ & [10] \\
\hline & R5'-GGATGTCCTGGCATGTCTCT & & \\
\hline \multirow[t]{2}{*}{ jhp0951 } & F5'-ATGCGTGGCTAAGCGATACT & $243 \mathrm{bp}$ & [19] \\
\hline & R5'-GACCCAACGCTCTTGAAGTT & & \\
\hline
\end{tabular}

The primer sequences used for the five genes were the same as the references. There were two pairs of primers used for jhp0940

$F$, forward primer sequence; $R$, reverse primer sequence

the genes was performed in a volume of $25 \mu$ l containing 25 pmol of both forward and reverse primers. The PCR conditions were $95{ }^{\circ} \mathrm{C}$ for $5 \mathrm{~min}$, followed by 35 cycles of $95{ }^{\circ} \mathrm{C}$ for $45 \mathrm{~s}, 52{ }^{\circ} \mathrm{C}$ for $45 \mathrm{~s}$, and $72{ }^{\circ} \mathrm{C}$ for $45 \mathrm{~s}$, and finally $72{ }^{\circ} \mathrm{C}$ for $5 \mathrm{~min}$. Two primer sets were used for the jhp0940 gene, and when the PCR using one pair was positive, the jhp0940 status was determined to be positive. The status of the genes was positive in strain J99 and negative in strain 26695.

\section{Statistical analysis}

The prevalence rates of all five genes were evaluated. The association between each genotype and the clinical outcomes were quantified using the chi-squared test. A probability $(p)$ value equal to or less than 0.05 was considered to be statistically significant, and a value of 0.001 or less was considered to be highly significant. Univariate analysis and a multivariate logistic regression model were used to calculate the odds ratios (ORs) of the clinical outcomes using SAS 9.3.

\section{Results}

Distribution of the jhp0940, jhp0945, jhp0947, jhp0949 and jhp0951 genes

The prevalence rates of jhp0940, jhp0945, jhp0947, jhp0949 and jhp0951 in the tested $H$. pylori were $42.55 \%$ (60/141), $51.06 \%$ (72/141), $20.57 \%$ (29/141), $56.03 \%(79 / 141)$ and $63.12 \%(89 / 141)$, respectively (Table 2).

\section{Geographic variation of plasticity region genes}

The results were divided into two groups based on their geographic variation. By comparing the results of the strains from HLJ Province and JX Province, we 
Table 2 The prevalence of the five genes in the CAG, PUD and GC isolates

\begin{tabular}{|c|c|c|c|c|c|}
\hline & \multirow{4}{*}{ Gene } & \multicolumn{4}{|l|}{$\mathrm{No}^{\mathrm{a}}(\%)$ found } \\
\hline & & \multirow{2}{*}{$\begin{array}{l}\text { CAG }^{\mathrm{b}} \\
\mathrm{HLJ}(n=20)\end{array}$} & \multirow{2}{*}{$\begin{array}{l}\operatorname{PUD}^{c} \\
H \sqcup(n=9)\end{array}$} & \multirow{2}{*}{$\begin{array}{l}\mathrm{GC}^{\mathrm{d}} \\
\mathrm{HLJ}(n=11)\end{array}$} & \multirow[t]{3}{*}{ Total $^{e}$} \\
\hline & & & & & \\
\hline & & $J X(n=38)$ & $J X(n=36)$ & $J X(n=27)$ & \\
\hline$\overline{H L J^{f}}$ & jhp0940 & $6(30 \%)$ & $3(33.33 \%)$ & $7(63.64 \%)$ & 16 (40 \%) \\
\hline \multicolumn{6}{|c|}{$n=40$} \\
\hline & jhp0945 & $5(25 \%)$ & 4 (44.44 \%) & 8 (72.73 \%) & 17 (42.5 \%) \\
\hline & jhp0947 & $2(10 \%)$ & 0 & 2 (18.18 \%) & $4(10 \%)$ \\
\hline & jhp0949 & $8(40 \%)$ & 7 (77.78 \%) & 6 (54.55 \%) & 21 (52.5 \%) \\
\hline & jhp0951 & 11 (55 \%) & 6 (66.67 \%) & 6 (54.55 \%) & $23(57.5 \%)$ \\
\hline$J X^{g}$ & jhp0940 & 14 (36.84 \%) & 19 (52.78 \%) & 11 (40.74 \%) & $44(43.56 \%$ \\
\hline \multicolumn{6}{|c|}{$n=101$} \\
\hline & jhp0945 & 11 (28.95 \%) & 24 (66.67 \%) & 20 (74.07 \%) & $55(54.46 \%)$ \\
\hline & jhp0947 & $2(5.26 \%)$ & $15(41.67 \%)$ & 8 (29.63 \%) & $25(24.75 \%$ \\
\hline & jhp0949 & 15 (39.47 \%) & 24 (66.67 \%) & 19 (70.37 \%) & $58(57.43 \%$ \\
\hline & jhp0951 & $20(52.63 \%)$ & $29(80.56 \%)$ & 17 (62.96 \%) & $66(65.35 \%$ \\
\hline \multicolumn{6}{|c|}{$\begin{array}{l}\text { The positive rates of each gene in the CAG, PUD and GC patients from HLJ } \\
\text { and JX Provinces } \\
\text { a No the number of positive isolates } \\
\text { bCAG chronic active gastritis } \\
\text { cPUD peptic ulcer disease } \\
{ }^{\mathrm{d}} G C \text { gastric carcinoma } \\
\text { e Total the total positive rate of each gene } \\
\text { fHL Heilongjiang Province, China } \\
{ }^{J} \text { J Jiangxi Province, China }\end{array}$} \\
\hline
\end{tabular}

found no significant differences in the prevalence of jhp0940 (40\%, 16/40 and $43.56 \%, 44 / 101$, respectively, $p=0.699)$, jhp0945 $(42.5 \%, 17 / 40$ and $54.46 \%$, $55 / 101, p=0.201)$, jhp0947 (10\%, 4/40 and $24.75 \%$, $25 / 101, \quad p=0.051), \quad j h p 0949 \quad(52.5 \%, 21 / 40$ and $57.43 \%, 58 / 101, p=0.595)$, or $j h p 0951$ (57.5\%, 23/40 and $65.35 \%, 66 / 101, p=0.384$ ).

\section{Plasticity region genes and diseases}

The prevalence rates of $j h p 0940$ in the strains from the CAG, PUD and GC patients were $34.48 \%$ (20/58), $48.89 \%$ $(22 / 45)$ and $47.37 \%(18 / 38)$, respectively, and there were no differences between the three diseases. The prevalence rates of jhp0945 in the isolates from the patients with PUD $(62.22 \%, 28 / 45)$ and GC $(73.68 \%, 28 / 38)$ were significantly higher than from the CAG patients $(27.59 \%, 16 / 58$; $p=0.0004$ and $p<0.0001$, respectively). The jhp0947 gene occurred in only $4(6.89 \%)$ of the strains isolated from the CAG patients, and the occurrence was much lower than in the PUD and GC patients $(33.33 \%, 15 / 45$ and $26.32 \%, 10 / 38 ; p=0.0006$ and $p=0.0084$, respectively). The prevalence of jhp0949 was similar (68.89\%, 31/ 45 and $65.79 \%, 25 / 38)$ in the PUD and GC isolates and was much higher than that in the CAG patients $(39.66 \%$, $23 / 58 ; p=0.0032$ and $p=0.0123$, respectively). For jhp0951, the prevalence rate in the PUD patients was higher than that in the CAG patients $(77.78 \%, 35 / 45$ and $53.45 \%, 31 / 58$, respectively; $p=0.0107)$; however, there was no difference between GC and CAG.

\section{The relationship between jhp0940, jhp0945, jhp0947, jhp0949 and jhp0951}

The status of all of the genes showed that they are significantly associated with each other (Table 3 ). The status of jhp0945 was associated with jhp0949 $(p=0.009)$ and jhp0951 ( $p=0.022)$. All of the jhp0947-positive isolates possessed jhp0949, and both were significantly associated with jhp0951 $(p=0.0008$ and $p<0.0001$, respectively).

When combining the five genes together, the majority of the genotypes were all negative or all positive (the $-/-/-/-/-$ genotype or the $+/+/+/+/+$ genotype, $12.06 \%, 17 / 141)$. The rates of the all-positive genotypes were $15.79 \%(6 / 38), 20 \%(9 / 45)$ and $3.45 \%(2 / 58)$ in the isolates from the patients with GC, PUD and CAG only, respectively. In contrast, the rates of the all-negative genotypes were $5.26 \%(2 / 38), 2.22 \%(1 / 45)$ and $24.14 \%(14 / 58)$ for GC, PUD, and CAG, respectively.

\section{The relationship between the gene status and the clinical outcomes}

A univariate analysis showed that there was no significant association between the jhp0940 status and the selected diseases (Table 4), but the status of jhp0945, jhp0947, jhp0949 and jhp0951 was significantly associated with a lower risk for CAG (odds ratio (OR), [95\% confidence interval (CI)], 0.176 [0.081 to 0.381 ]; 0.116 [0.035 to 0.389$] ; 0.300$ [0.145 to 0.623 ] and 0.445 [0.214 to 0.928 ], respectively). On the converse, they were also related to an increased risk for PUD (OR [95 \% CI], 2.306 [1.08 to 4.927]; 2.835 [1.191 to 6.751], 2.452 [1.126 to 5.336 ] and 2.825 [1.226 to 6.51], respectively). Moreover, only the jhp0945-positive isolates were associated with an increased risk for GC (OR, 5.9259; 95 \% CI, 1.267 to 27.714 ).

A multivariate analysis, including age and jhp0940, jhp0945, jhp0947, jhp0949 and jhp0951 status, was performed to determine the factors that were related to the

Table 3 The relationship between the different plasticity region genes

\begin{tabular}{lllll}
\hline & \multicolumn{4}{l}{ Relationship (coefficient value $/ p$ value) } \\
\cline { 2 - 5 } gene & jhp0945 & jhp0947 & jhp0949 & jhp0951 \\
\hline jhp0940 & $0.183 / 0.03$ & $0.236 / 0.005$ & $0.184 / 0.029$ & $0.182 / 0.031$ \\
jhp0945 & - & $0.358 /<0.0001$ & $0.219 / 0.009$ & $0.193 / 0.022$ \\
jhp0947 & - & - & $0.415 /<0.0001$ & $0.280 / 0.0008$ \\
jhp0949 & - & - & - & $0.478 /<0.0001$ \\
\hline
\end{tabular}

The coefficient value for assessing the association between each pair of genes. A $p$ value of 0.001 or less was considered to be highly significant

The coefficient value ${ }^{\mathrm{a}}$ was analyzed using Fisher's test 
Table 4 The relationship between each gene and the clinical outcomes

\begin{tabular}{|c|c|c|c|c|c|c|c|c|c|}
\hline \multirow[b]{2}{*}{ gene } & \multirow[b]{2}{*}{$O R^{d}$} & \multicolumn{3}{|l|}{$C A G^{a}$} & \multicolumn{2}{|l|}{ PUD $^{b}$} & \multicolumn{3}{|l|}{$\mathrm{GC}^{\mathrm{C}}$} \\
\hline & & $95 \% \mathrm{Cl}^{\mathrm{e}}$ & $p$ & OR & $95 \% \mathrm{Cl}$ & $p$ & $\overline{\mathrm{OR}}$ & $95 \% \mathrm{Cl}$ & $p$ \\
\hline jhp0940 & 0.488 & $0.235-1.013$ & 0.054 & 1.449 & $0.694-3.026$ & 0.323 & 1.822 & $0.734-4.523$ & 0.196 \\
\hline jhp0945 & 0.176 & $0.081-0.381$ & $<0.0001$ & 2.306 & $1.08-4.927$ & 0.031 & 3.542 & $1.362-9.209$ & 0.009 \\
\hline jhp0947 & 0.116 & $0.035-0.389$ & 0.0005 & 2.835 & $1.191-6.751$ & 0.019 & 2.307 & $0.765-6.952$ & 0.134 \\
\hline jhp0949 & 0.300 & $0.145-0.623$ & 0.0012 & 2.452 & $1.126-5.336$ & 0.024 & 2.067 & $0.812-5.26$ & 0.128 \\
\hline jhp0951 & 0.445 & $0.214-0.928$ & 0.031 & 2.825 & $1.226-6.51$ & 0.015 & 1.008 & $0.403-2.517$ & 0.987 \\
\hline
\end{tabular}

The univariate analysis showing the association between each gene status and the indicated disease

${ }^{a} C A G$ chronic active gastritis

${ }^{b} P U D$ peptic ulcer disease

${ }^{\mathrm{G}} \mathrm{GC}$ gastric carcinoma

${ }^{\mathrm{d} O R}$ odds ratio

${ }^{\mathrm{e}} \mathrm{Cl}$ confidence interval

clinical outcomes of the selected diseases (Table 5). The jhp0945 status for GC and the jhp0951 status for PUD significantly increased the risk of a clinical outcome. In contrast, the jhp0945 or jhp0949 status significantly decreased the risk for CAG (OR [95 \% CI]: 0.214 [0.099 to 0.466 ]; 0.373 [0.172 to 0.807], respectively). Age significantly decreased the risk of CAG and PUD (OR [95 \% CI]: 0.964 [0.937 to 0.992 ]; 0.963 [0.937 to 0.991], respectively), while it increased the risk for GC (1.098 [1.059 to 1.139]).

\section{Discussion}

The plasticity region is a recently identified locus found in the chromosome of $H$. pylori strains $J 99$ and 26695 that displays similar characteristics to pathogenicity islands $[7,8]$. The majority of the $H$. pylori strainspecific genes that are transferred from other species are located in the plasticity region $[9,12,13]$. The genes present in the plasticity region have been highlighted as potential pathogenic markers and may account for the differences in the $H$. pylori strain virulence, resulting in various clinical outcomes.

The jhp0940, jhp0945, jhp0947, jhp0949 and jhp0951 genes, which are specific for strain J99, have recently

Table 5 A multivariate analysis of the risk for CAG, PUD and GC based on age and the status of all five genes

\begin{tabular}{lllll}
\hline Disease & Parameter & $\mathrm{OR}^{\mathrm{d}}$ & $95 \% \mathrm{Cl}^{\mathrm{e}}$ & $p$ value \\
\hline CAG $^{\mathrm{a}}$ & jhp0945 & 0.214 & $0.099-0.466$ & 0.0001 \\
& jhp0949 & 0.373 & $0.172-0.807$ & 0.0123 \\
& age & 0.964 & $0.937-0.992$ & 0.0111 \\
PUD $^{b}$ & jhp0951 & 2.821 & $1.224-6.499$ & 0.0149 \\
& age & 0.963 & $0.937-0.991$ & 0.0089 \\
GC $^{c}$ & jhp0945 & 3.460 & $1.351-8.865$ & 0.0097 \\
& age & 1.098 & $1.059-1.139$ & $<0.0001$ \\
\hline
\end{tabular}

${ }^{a} C A G$ chronic active gastritis

${ }^{\mathrm{b}}$ PUD peptic ulcer disease

${ }^{\mathrm{C}} \mathrm{GC}$ gastric carcinoma

${ }^{\mathrm{d} O R}$ odds ratio

${ }^{\mathrm{e}} \mathrm{Cl}$ confidence interval been reported to be associated with $H$. pylori-related diseases and are potential markers for the risk of gastrointestinal diseases [10]. Because of their geographic variation, the relationship between these genes and the severity of certain diseases has been discussed, but the results are often not in agreement. The prevalence of these genes and their relationship with certain diseases in China is currently unknown; therefore, we examined the distribution of these virulence markers and their relationship to the clinical outcomes of patients infected with H. pylori.

Previous study found that there were no significant associations between the gastroduodenal diseases and the status of jhp0940, jhp0945 and jhp0949 in East Asia strains [10]. Yakoob et al. demonstrated that jhp0940 and jhp0947 in Pakistan strains were associated with GC and PUD [14]. In our study, there was no association between $j h p 0940$ and diseases. The positive rates of jhp0945, jhp0947, jhp0949 and jhp0951 were much higher in PUD, and there was a significant association between the genes. However, the multivariate analysis showed that only jhp0951 was independently associated with the development of PUD in our study. Jhp0951, which encodes an integrase from the XerCD family, is involved in the response to acidic environments [15]. In DUs, acid secretion increases, causing the mucosa to be continuously exposed to a low $\mathrm{pH}$, which is consistent with our results [9]. As the virulence genes were associated with each other in our study, the strong linkage of jhp0945, jhp0947 and jhp0949 with PUD may be due to the significant association between jhp0951 and PUD. We also speculate that all of these factors act synergistically in causing damage to the host.

It is well known that the development of GC is marked by a slow progression that begins with $H$. pylori-induced chronic superficial gastritis, which then progresses to atrophic gastritis, intestinal metaplasia, dysplasia and eventually GC $[16,17]$. In our study, the multivariate analysis showed that the only independent virulence gene that 
increased the risk of GC was jhp0945, indicating a significant association between the two. However, the jhp0945 status showed a negative association with CAG (Table 5), which conflicts with the process of GC development. In our study, we speculate that the majority of the individuals with CAG do not carry the jhp0945 gene, while the few jhp0945-positive individuals potentially develop GC due to a combination of the bacteria, the host and other environmental factors, which is consistent with the fact that of the $H$. pylori-infected individuals, $80-90 \%$ have clinically asymptomatic gastritis, while only 1-2 \% develop GC [18]. Jhp0945-positive isolates may be more likely to develop severe diseases, and jhp0945 status may be a risk indicator for GC development. Additional prospective studies are still necessary to further confirm our speculations.

\section{Conclusions}

In conclusion, this was the first study in China to evaluate the relationship between plasticity region genes and clinical disease outcomes. We found that jhp0951 status is an independent factor for discriminating PUD and may influence the association of other virulence factors with certain diseases. Jhp0945 may predict the future development of GC in patients with CAG and is considered to be the best candidate disease marker for $H$. pylori-related diseases.

\section{Abbreviations}

H. pylori: Helicobacter pylori; CAG: Chronic active gastritis; PUD: Peptic ulcer disease; GC: Gastric carcinoma; HLJ: Heilongjiang; JX: Jiangxi; OR: Odds ratio; $\mathrm{Cl}$ : Confidence interval.

\section{Competing interests}

The authors declare that they have no competing interests.

\section{Authors' contributions}

ZJZ designed the research. GYN performed the study and wrote the paper. $\mathrm{PXH}$ and $\mathrm{LH}$ analyzed the results. $\mathrm{HLH}$ and $\mathrm{YYH}$ participated in strains recovery. All authors read and approved the final manuscript.

\section{Acknowledgments}

This study was supported by the Grant from National Technology R \& D Program in the 12th Five-Year Plan of China (No. 2012BAI06B02), the Major Technology Project as part of "Prevention and Control of Major Infectious Diseases including AIDS and Viral Hepatitis" (No. 2013ZX10004216-002) and the grant from National Key Scientific Instrument and Equipment Development Project (No. 2012YQ180117).

We would like to thank all of the participants from the Department of Diagnosis for Communicable Diseases, the National Institute for Communicable Disease Control and Prevention, and the Chinese Center for Disease Control and Prevention.

Received: 24 April 2015 Accepted: 25 August 2015

Published online: 10 September 2015

\section{References}

1. Parsonnet J, Friedman GD, Vandersteen DP, Chang Y, Volgeman JH, Orentreich $\mathrm{N}$, et al. Helicobacter pylori infection and the risk of gastric carcinoma. N Engl J Med. 1991;325:1127-31.

2. Uemura N, Okamoto S, Yamamoto S, Matsumura N, Yamaguchi S, Yamakido $M$, et al. Helicobacter pylori infection and the development of gastric cancer. N Engl J Med. 2001;345:784-9.
3. Occhialini A, Marais A, Richard A, Garcia F, Sierra R, Mégraud F. Distribution of Open Reading Frames of Plasticity Region of Strain $J 99$ in Helicobacter pylori Strains Isolated from Gastric Carcinoma and Gastritis Patients in Costa Rica. Infect Immun. 2000;68:6240-9.

4. Santos A, Queiroz DM, Ménard A, Marais A, Rocha GA, Oliveira CA, et al. New pathogenicity marker found in the plasticity region of the Helicobacter pylori genome. J Clin Microbiol. 2003;41:1651-5.

5. Backert S, Schwarz T, Miehlke S, Kirsch C, Sommer C, Kwok T, et al. Functional analysis of the cag pathogenicity island in Helicobacter pylori isolates from patients with gastritis, peptic ulcer, and gastric cancer. Infect Immun. 2004;72:1043-56.

6. Yamaoka Y. Mechanisms of disease: Helicobacter pylori virulence factors. Nat Rev Gastroenterol Hepatol. 2000;7:629-41.

7. Alm RA, Ling LS, Moir DT, King BL, Brown ED, Doig PC, et al. Genomicsequence comparison of two unrelated isolates of the human gastric pathogen Helicobacter pylori. Nature. 1999;397:176-80.

8. Doig P, de Jonge BL, Alm RA, Brown ED, Uria-Nickelsen M, Noonan B, et al. Helicobacter pylori physiology predicted from genomic comparison of two strains. Microbiol Mol Biol Rev. 1999;63:675-707.

9. Romo-González C, Salama NR, Burgeño-Ferreira J, Ponce-Castañeda V, Lazcano-Ponce E, Camorlinga-Ponce M, et al. Differences in genome content among Helicobacter pylori isolates from patients with gastritis, duodenal ulcer, or gastric cancer reveal novel disease-associated genes. Infect Immun. 2009;77:2201-11.

10. Sugimoto M, Watada M, Jung SW, Graham DY, Yamaoka Y. Role of Helicobacter pylori Plasticity Region Genes in development of Gastroduodenal Diseases. J Clin Microbiol. 2012;50:441-8.

11. Proença Módena JL, Lopes Sales Al, Olszanski Acrani G, Russo R, Vilela Ribeiro MA, Fukuhara Y, et al. Association between Helicobacter pylori genotypes and gastric disorders in relation to the cag pathogenicity island. Diagn Microbiol Infect Dis. 2007;59:7-16.

12. Rizwan M, Alvi A, Ahmed N. Novel protein antigen (JHP940) from the genomic plasticity region of Helicobacter pylori induces tumor necrosis factor alpha and interleukin-8 secretion by human macrophages. J Bacteriol. 2008;190:1146-51.

13. de Jonge R, Kuipers EJ, Langeveld SC, Loffeld RJ, Stoof J, van Vliet AH, et al. The Helicobacter pylori plasticity region locus jhp0947-jhp0949 is associated with duodenal ulcer disease and interleukin-12 production in monocyte cells. FEMS Immunol Med Microbiol. 2004:41:161-7.

14. Yakoob J, Abbas Z, Nas S, Islam M, Abid S, Jafri W. Associations between the plasticity region genes of Helicobacter pylori and gastroduodenal diseases in a high-prevalence area. Gut and Liver. 2010;4:345-50.

15. Gancz H, Censini S, Merrell DS. Iron and pH homeostasis intersect at the level of Fur regulation in the gastric pathogen Helicobacter pylori. Infect Immun. 2006;74:602-14.

16. Conteduca V, Sansonno D, Lauletta G, Russi S, Ingravallo G, Dammacco F. H. pylori infection and gastric cancer: State of the art. Int J Oncol. 2013;42:5-18.

17. Matysiak-Budnik T, Mégraud F. Helicobacter pylori infection and gastric cancer. Eur J Cancer. 2006:42:708-16.

18. Wu MS, Chow LP, Lin JT, Chiou SH. Proteomic identification of biomarkers related to Helicobacter pylori-associated gastroduodenal disease: Challenges and opportunities. J Gastroenterol Hepatol. 2008;23:1657-61.

19. Watada M, Shiota S, Matsunari O, Suzuki R, Murakami K, Fujioka T, et al. Association between Helicobacter pylori cagA-related genes and clinical outcomes in Colombia and Japan. BMC Gastroenterol. 2011;11:141-8. 